\title{
Toxicity of the aromatase inhibitor letrozole to Japanese medaka (Oryzias latipes) eggs, larvae and breeding adults
}

\author{
Liwei Sun $^{\text {a }}$, Jinmiao Zha ${ }^{\text {a }}$, Philip A. Spear ${ }^{\mathrm{b}}$, Zijian Wang ${ }^{\mathrm{a}, *}$ \\ ${ }^{\text {a }}$ State Key Laboratory of Environmental Aquatic Chemistry, Research Center for Eco-Environmental Sciences, Chinese Academy of Sciences, \\ P. O. Box 2871, Beijing, 100085, P. R. China \\ ${ }^{\mathrm{b}}$ Centre de recherche TOXEN, Université du Québec à Montréal, Case Postale 8888, Succursale Centre-ville, Montréal, Québec, Canada H3C $3 P 8$
}

Received 30 October 2006; received in revised form 11 January 2007; accepted 11 January 2007

Available online 22 February 2007

\begin{abstract}
Letrozole is a synthetic aromatase inhibitor and interferes in the committed step in the synthesis of endogenous estrogens from androgens. To evaluate potential effects on the early life stages of Japanese medaka, larvae and fertilized eggs were exposed to letrozole for $96 \mathrm{~h}$ and 14 days, respectively. No larvae died and no adverse effects were found on embryonic development at concentrations up to $3125 \mu \mathrm{g} / \mathrm{L}$. Reproductive effects were assessed by exposing adults to $1,5,25,125$ and $625 \mu \mathrm{g} / \mathrm{L}$ letrozole for 21 days. A dose-dependent decrease in fecundity ( $>25 \mu \mathrm{g} / \mathrm{L}$ ) and fertility $(>5 \mu \mathrm{g} / \mathrm{L})$ accompanied by histological changes suggested the inhibition of oocyte growth and possibly maturation. At $625 \mu \mathrm{g} / \mathrm{L}$, the fish ceased spawning during the last week of exposure. Letrozole $(>5 \mu \mathrm{g} / \mathrm{L})$ reduced plasma vitellogenin levels in females in a dose-dependent manner. Transgenerational effects were evaluated by removing freshly-laid F1 eggs from letrozole-contaminated water and raising them to 15 days post-hatching in control water. Hatchability and time to hatching were detrimentally affected ( $>5 \mu \mathrm{g} / \mathrm{L})$, but no morphological deformities were observed. Furthermore, a dose-dependent increase in the proportion of genotypic F1 males was found $(>5 \mu \mathrm{g} / \mathrm{L})$.
\end{abstract}

(C) 2007 Elsevier Inc. All rights reserved.

Keywords: Endocrine disrupting chemical; Sex ratio; Transgenerational effects; Vitellogenin; Estrogen; Teleost

\section{Introduction}

Aromatase is a cytochrome P450 enzyme found in many tissues including the ovary, fat, muscle, liver and breast. Cytochrome P450 aromatase (CYP19) is responsible for the final step in estrogen biosynthesis, catalyzing the aromatization of androstenedione and testosterone into estrone and estradiol (E2), respectively (Haynes et al., 2003). As such, aromatase inhibitors (AIs) have been used to treat metastatic breast cancer for over 25 years (Howell and Buzdar, 2005). Recently, some more potent, better tolerated, and more selective AIs, such as the non-steroidal competitive inhibitors letrozole and anastrozole and the steroidal irreversible inhibitor exemestane, have been introduced and entered into widespread clinical use (Seralini and Moslemi, 2001; Haynes et al., 2003).

\footnotetext{
* Corresponding author. State Key Laboratory of Environmental Aquatic Chemistry, Research Center for Eco-Environmental Sciences, Shuangqing Rd 18, Haidian District, Beijing, 100085, P. R. China. Tel./fax: +86 1062849140. E-mail address: wangzj@rcees.ac.cn (Z. Wang).
}

Letrozole (CGS 20267), with commonly used brand name Femara, is a non-steroidal triazole derivative and one of the most potent aromatase inhibitors yet developed (Smith, 1999). It has been approved for the first-line therapy for hormonereceptor positive, metastatic breast cancer in postmenopausal women (Haynes et al., 2003). It has potential for use both to prevent the conversion of androgenic steroids to estrogens and to prevent or diminish the side effects of androgenic steroid abuse (Haynes et al., 2003). Letrozole is capable of inhibiting aromatase $98-99 \%$ and reducing serum concentrations of estrone and E2 beyond the limit of detection in patients (Smith, 1999).

Increased attention is currently being paid to pharmaceutical substances as a class of environmental contaminants (HallingSorensen et al., 1998; Hilton and Thomas, 2003; Ashton et al., 2004). Like other human pharmaceutical compounds, AIs can enter aquatic systems in their native form or as metabolites, and cause ecotoxicological effects. Moreover, the AIs have been administered intentionally in aquaculture to regulate sex differentiation of fish ( $\mathrm{Li}$ et al., 2005). Besides letrozole and 
other related pharmaceuticals, a large number of chemicals present in the environment, including some fungicides and isoflavonic phytoestrogens, were found to inhibit aromatase activity (Seralini and Moslemi, 2001; Ankley et al., 2002).

The high activity of aromatase in teleosts suggests that this enzyme constitutes a potential target for endocrine disrupting chemicals (EDCs) (Melo and Ramsdell, 2001). There is increasing evidence in fish that multiple loci exist encoding at least two distinct isozymes of CYP19 that are differentially expressed in the brain and ovary (Kuhl et al., 2005). The potential for aromatase inhibitors to adversely affect sexual differentiation and reproduction in fish was demonstrated in an early study by Piferrer et al. (1994), and similar results have been reported by Afonso et al. (1999, 2000), Kitano et al. (2000), Ankley et al. (2002), and Panter et al. (2002).

Relatively high doses were needed to elicit a response in these studies and the environmental significance of aromatase inhibition has been questioned (U.S.EPA, 2002). However, a study of perch (Perca fluviatilis) collected from a Swedish lake that was receiving drainage from a nearby landfill reported an association between decreased brain aromatase activity, circulating E2 levels and ovarian somatic index in females (Noaksson et al., 2001). This observation suggested that aromatase inhibition could be an important mechanism of action for environmental contaminants in fish, wildlife and humans. To our knowledge, neither the toxicity of letrozole, nor its potential to disrupt reproductive functions in fish has been studied in depth.

Medaka is recognized as an appropriate model for the evaluation of EDCs (Patyna et al., 1999; Ishibashi et al., 2004). In particular, its large eggs with clear chorions facilitate the observation of embryos. The early life stages of medaka are also considered to be relatively sensitive to toxic chemicals (Chikae et al., 2004). The objective of this study was to evaluate the effects of letrozole on reproductive performance and early life stages of the Japanese medaka.

\section{Materials and methods}

\subsection{Test chemical}

Letrozole (purity $>98.0 \%$ ) was obtained from Beijing Dezhong-Venture Pharmaceutical Technology Development Co., Ltd., China. Due to the low solubility of letrozole in water $\left(0.144 \mathrm{mmol} / \mathrm{L}\right.$ at $\left.25^{\circ} \mathrm{C}\right)$, the stock solution was prepared in HPLC-grade acetone (Fisher Scientific, USA). All other chemicals were analytical or HPLC grade (Sigma Chemical Co. USA, or Beijing Chemical Reagents Company, China).

\subsection{Test fish}

Japanese medaka (d-rR) were kindly provided by the Laboratory of Freshwater Fish at the Bioscience Center of Nagoya University, Japan. The brood stock has been maintained in our laboratory for more than 4 years. Japanese medaka were kept in charcoal-dechlorinated tap water $(\mathrm{pH} 7.2-7.6$; hardness $\left.44.0-61.0 \mathrm{mg} \mathrm{CaCO}_{3} / \mathrm{L}\right)$ at a constant temperature $\left(25 \pm 1{ }^{\circ} \mathrm{C}\right)$, with a photoperiod of 16:8 h (light:dark). The brood stock was fed three times daily, once with newly hatched brine shrimp (Artemia sp.) and twice with commercial fish food (TetraMin ${ }^{\circledR}$ ).

\subsection{Exposure conditions for embryos and larvae}

Eggs spawned from stock females were carefully collected within $4 \mathrm{~h}$ of fertilization. Egg clutches were pooled and separated. Eggs were then disinfected by placing them in a $0.9 \%$ solution of hydrogen peroxide for $10 \mathrm{~min}$ and checked for fertilization using a dissecting microscope. For each exposure level, 90 embryos were randomly separated into three equal groups (i.e. triplicate groups/exposure). Based on the results of an initial range-finding study (data not shown), embryos were exposed for 14 days to nominal letrozole concentrations of 1,5 , $25,125,625$, and $3125 \mu \mathrm{g} / \mathrm{L}$ in dilution water containing $1 \%$ methylene blue. In addition, dilution water controls (DWC) containing $1 \%$ methylene blue and solvent controls (SC) containing $0.1 \%$ acetone were included in the experimental design. The embryos in each group were placed in a glass dish containing $100 \mathrm{~mL}$ of test solution and incubated on a 16:8-h light:dark photoperiod cycle at $25 \pm 1{ }^{\circ} \mathrm{C}$. The test solution was $80 \%$ renewed every $24 \mathrm{~h}$. Embryos were observed twice daily at which time dead ones (identified by the incorporation of methylene blue) were removed. Twenty $12 \mathrm{~h}$-old larvae from each treatment were placed in glass beakers containing $150 \mathrm{~mL}$, and triplicate beakers were prepared for each test solution. Larvae were not fed during the 96-h exposure period. The exposure conditions (including water temperature and photoperiod) and letrozole concentrations for larvae were the same as those for embryos. The test solutions were $80 \%$ renewed every $24 \mathrm{~h}$. The larvae were observed twice daily and dead larvae, characterized by no heart activity, were removed.

\subsection{Exposure conditions for reproducing medaka}

Breeding pairs of medaka (approximately 5 months old) were acclimated for 3 weeks in flow-through 15-L glass aquaria (conditions as in Section 2.2). During the last week of acclimation, the newly-spawned eggs were collected daily a few hours after oviposition, counted, and assessed for fertility. Based on the number and viability of their eggs, 84 breeding pairs of medaka were selected for the reproductive test. Six pairs were randomly assigned to a $15-\mathrm{L}$ glass aquarium and duplicate aquaria were used at each exposure level. A dilution apparatus equipped with a peristaltic pump and mixing chambers supplied a constant flow equivalent to 7 times the aquaria volume per day. Fish were exposed to nominal letrozole concentrations of 1 , $5,25,125$ and $625 \mu \mathrm{g} / \mathrm{L}$. The SC aquaria and all letrozole exposure aquaria received $0.1 \mathrm{~mL} / \mathrm{L}$ acetone whereas the DWC received dechlorinated tap water only.

The test duration was 21 days and the feeding regime was maintained throughout the exposure period. The aquaria were cleaned twice a week. During the last week of exposure, newlyspawned eggs were carefully collected within a few hours after fertilization. The number of eggs spawned in each treatment group was counted, and the ratio of fertilized eggs was 
calculated. Each embryo was maintained in dechlorinated tap water and observed daily. Hatchability, time to hatching and gross abnormality rate were recorded. Once hatched, the larvae were maintained for 15 days and the genetic sex ratio was determined by the color of the fish. In the d-rR strain of medaka, sex-linked genes determine orange-red coloration in males and white in females (Yamamoto, 1953; Edmunds et al., 2000). At the end of the F0 generation exposure, adult fish were killed and tissues prepared for histological evaluation and plasma vitellogenin (VTG) assays. The body weight measured, and the livers and gonads were sampled. The gonadosomatic (GSI, \%) and hepatosomatic indices (HSI, \%) were calculated as a ratio of gonad or liver weight to body weight.

\subsection{Blood sampling and measurement of plasma vitellogenin}

Fish were kept on ice for 1-2 min, and bled by severing the caudal peduncle. Blood was collected in a heparinized microcapillary tube, the volume measured, and the blood sample was added to a sampling buffer (20 mM Tris, $1 \mathrm{mM}$ EDTA, $150 \mathrm{mM}$ $\mathrm{NaCl}$, and $25 \mathrm{KIU} / \mathrm{mL}$ aprotinin at $\mathrm{pH} 7.5$ ). The samples were immediately centrifuged $\left(8000 \times g, 10 \mathrm{~min}, 4{ }^{\circ} \mathrm{C}\right)$, and the plasma stored at $-80^{\circ} \mathrm{C}$.

Plasma VTG levels were measured using a competitive enzyme-linked immunosorbent assay (ELISA). The procedure was performed according to the method described previously (Brion et al., 2002). The working range of the assay was from 30 to $1500 \mathrm{ng} / \mathrm{mL}$, and the detection limit was $15 \mathrm{ng} / \mathrm{mL}$ for purified VTG. To avoid the matrix effect, a dilution of at least 1:100 was chosen for the routine assay. Purified medaka VTG was used as a standard, and VTG in diluted samples was measured in triplicate.

\subsection{Histological analysis}

The gonads were excised, fixed in Bouin's solution and prepared for histological analysis according to standard procedures. The fixed tissues were processed routinely, dehydrated, and then embedded in paraffin wax. Serial longitudinal sections (thickness 4-5 $\mu \mathrm{m}$ ) were made from the preserved tissues. The sections were stained with hematoxylin and eosin ( $\mathrm{H}$ and $\mathrm{E})$, and then examined under a light microscope.

\subsection{Determination of letrozole concentrations in test water}

The letrozole concentration in the test water of each treatment group was measured twice a week during the exposure period. The analytical method was performed as described by Pfister et al. (1994) and Marfil et al. (1996) with some modifications. Briefly, the water sample of the flow-through renewal system was transferred to the separatory funnel, and dichloromethane was added. After extraction, the organic phase was mixed with anhydrous sodium sulfate for dehydration. This solution was then evaporated under a stream of nitrogen at room temperature. The remaining residue was dissolved in the mobile phase (described below) and stored at $-20{ }^{\circ} \mathrm{C}$.

Chromatography was carried out using a high performance liquid chromatography system (Dionex, US) with a variable
Table 1

Hatchability, time to hatching, and gross abnormality rate of fertilized eggs exposed to letrozole for 14 days

\begin{tabular}{llll}
\hline $\begin{array}{l}\text { Nominal concentrations } \\
(\mu \mathrm{g} / \mathrm{L})\end{array}$ & $\begin{array}{l}\text { Hatchability } \\
(\%)\end{array}$ & $\begin{array}{l}\text { Time to hatching } \\
(\text { days })\end{array}$ & $\begin{array}{l}\text { Gross abnormality } \\
\text { rate }(\%)\end{array}$ \\
\hline $\mathrm{DWC}$ & $91.0 \pm 4.2$ & $9.18 \pm 0.21$ & $2.8 \pm 3.2$ \\
$\mathrm{SC}$ & $93.8 \pm 3.3$ & $9.20 \pm 0.13$ & $1.9 \pm 1.9$ \\
1 & $89.9 \pm 4.0$ & $9.19 \pm 0.15$ & $4.3 \pm 3.1$ \\
5 & $89.6 \pm 5.5$ & $9.20 \pm 0.14$ & $1.9 \pm 1.9$ \\
25 & $91.9 \pm 4.1$ & $9.25 \pm 0.28$ & $1.1 \pm 1.9$ \\
125 & $92.4 \pm 4.2$ & $9.31 \pm 0.21$ & $0.9 \pm 1.6$ \\
625 & $92.0 \pm 6.3$ & $9.03 \pm 0.08$ & 0.0 \\
3125 & $91.0 \pm 3.1$ & $9.19 \pm 0.17$ & 0.0 \\
\hline
\end{tabular}

Data are the mean \pm S.D. DWC: diluted water control; SC: solvent control.

wavelength detector set as $234 \mathrm{~nm}$. The analytical column was a SymmetryShield ${ }^{\mathrm{TM}} \mathrm{RP}_{18}, 5 \mu \mathrm{m}, 150 \times 3.9 \mathrm{~mm}$ column (Waters, US). The sample was passed through a $0.22 \mu \mathrm{m}$ filter, and then injected through a $20-\mu 1$ injection loop. With a $0.8 \mathrm{~mL} / \mathrm{min}$ flow rate and an isocratic mobile phase of $70 \%$ phosphate buffer $(0.01 \mathrm{M} ; \mathrm{pH} 7.0)$ and $30 \%$ acetonitrile $(\mathrm{v} / \mathrm{v})$, the retention time was about $12 \mathrm{~min}$. A 7-point standard curve covering the range anticipated in this study was constructed by plotting peak area versus the concentration of letrozole. The correlation coefficient $\left(R^{2}\right)$ was greater than 0.999 , mean recovery was $96.6 \%$ and the coefficient of variation was $6.1 \%$.

\subsection{Statistical analysis}

Prior to data analysis, $\chi^{2}$ analyses, Student $t$-tests (parametric data) or Mann-Whitney rank sum tests (nonparametric, nonequal variances) were used to test for differences between DWC and SC groups. In all cases, the two control groups were not different and were therefore pooled for subsequent analyses. The experimental data were checked for assumptions of normality and homogeneity of variance using Kolmogorov-Smirnov one-sample test and Levene's test, respectively. When the assumptions were met, the data were subjected to one-way analysis of variance (ANOVA) with specific means comparisons by Dunnett's test. When data failed either test, the nonparametric Kruskal-Wallis test was used. When VTG value was not detected in male fish, we used the detection limit as the VTG value. In order to avoid biases associated with sizespecific indices (Packard and Boardman, 1999; Kang et al., 2002), analysis of covariance (ANCOVA) with body weight of medaka as a covariate was used to compare the GSI and HSI among all experimental groups. The data pertaining to sex ratios were assessed by $\chi^{2}$ analysis. The critical value for statistical significance was $p \leq 0.05$. All statistical analyses were completed by using SPSS 13.0 (SPSS, Chicago, IL, USA) and Origin 7.0 (OriginLab, Northampton, MA, USA).

\section{Results}

\subsection{Effects on the early life stages of medaka}

Hatchability, time to hatching, and gross abnormality rate of fertilized eggs exposed to letrozole for 14 days are shown in 
Table 2

Concentration of letrozole in water of the flow-through renewal system over the 21 days

\begin{tabular}{ll}
\hline Nominal concentration $(\mu \mathrm{g} / \mathrm{L})$ & Measured concentration $(\mu \mathrm{g} / \mathrm{L})$ \\
\hline DWC & $\mathrm{Nd}$ \\
$\mathrm{SC}$ & $\mathrm{Nd}$ \\
1 & $0.81 \pm 0.13$ \\
5 & $4.73 \pm 0.62$ \\
25 & $23.51 \pm 2.12$ \\
125 & $114.50 \pm 13.52$ \\
625 & $558.94 \pm 56.30$ \\
\hline
\end{tabular}

Data are the mean \pm S.D. DWC: diluted water control; SC: solvent control. Nd: not detected.

Table 1. Gross abnormalities were characterized as in Nimrod and Benson (1998), one of the most common being scoliosis. No significant differences were found for any endpoints among DWC, SC and letrozole-exposed groups. No larvae died during the 96-h exposure period even at $3125 \mu \mathrm{g} / \mathrm{L}$ letrozole (data not shown).

\subsection{Effects on the reproduction of medaka}

\subsubsection{Letrozole concentrations in the test water}

The letrozole concentrations measured in water of the flowthrough system over the 21 days are shown in Table 2. Water concentrations of letrozole were stable and relatively close to the target value (above $90 \%$ of their nominal values in all groups except in $1 \mu \mathrm{g} / \mathrm{L}(81 \%))$. Letrozole concentrations in the DWC and SC treatments were less than the limit of detection for all analyses.

\subsubsection{Effects in adults}

Levels of HSI and GSI in adult male and female medaka exposed to letrozole for 21 days are shown in Fig. 1. Although levels of HSI and GSI of male and female medaka were affected in all letrozole-exposed groups, there were no dose-response relationships between these parameters and letrozole exposure level. The HSI of male medaka increased, and significant differences were found in the $25 \mu \mathrm{g} / \mathrm{L}$ and $625 \mu \mathrm{g} / \mathrm{L}$ treatment relative to the controls $(p<0.05)$. The GSI of male medaka exposed to $125 \mu \mathrm{g} / \mathrm{L}$ and $625 \mu \mathrm{g} / \mathrm{L}$ letrozole were significantly higher than those of the control fish $(p<0.05$ and $p<0.01$, respectively). Letrozole caused a reduction in the HSI of females, and significant differences were found in the three high exposure groups relative to that of the controls $(p<0.05)$. Further, the GSI of female medaka increased when exposed to letrozole, and in the $625 \mu \mathrm{g} / \mathrm{L}$ group the increase was statistically significant $(p<0.01)$.

Representative gonadal sections of female and male medaka from this study are shown in Fig. 2. There were marked effects on the ovaries, particularly from fish in the highest
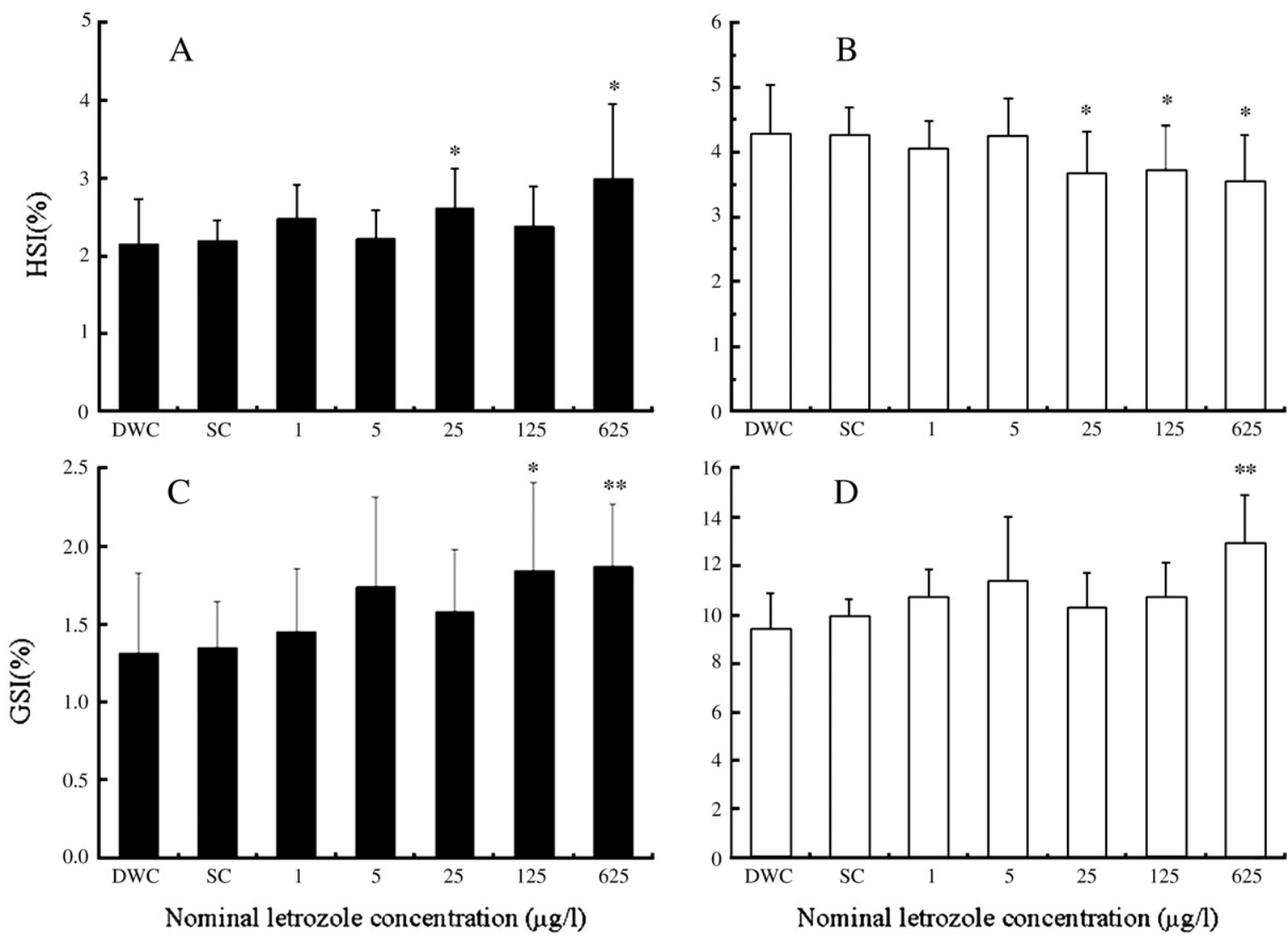

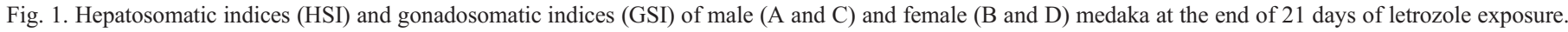

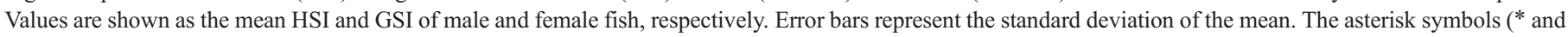
**) denote significantly different when compared to the controls as $p<0.05$ and $p<0.01$, respectively. DWC: diluted water control; SC: solvent control. 

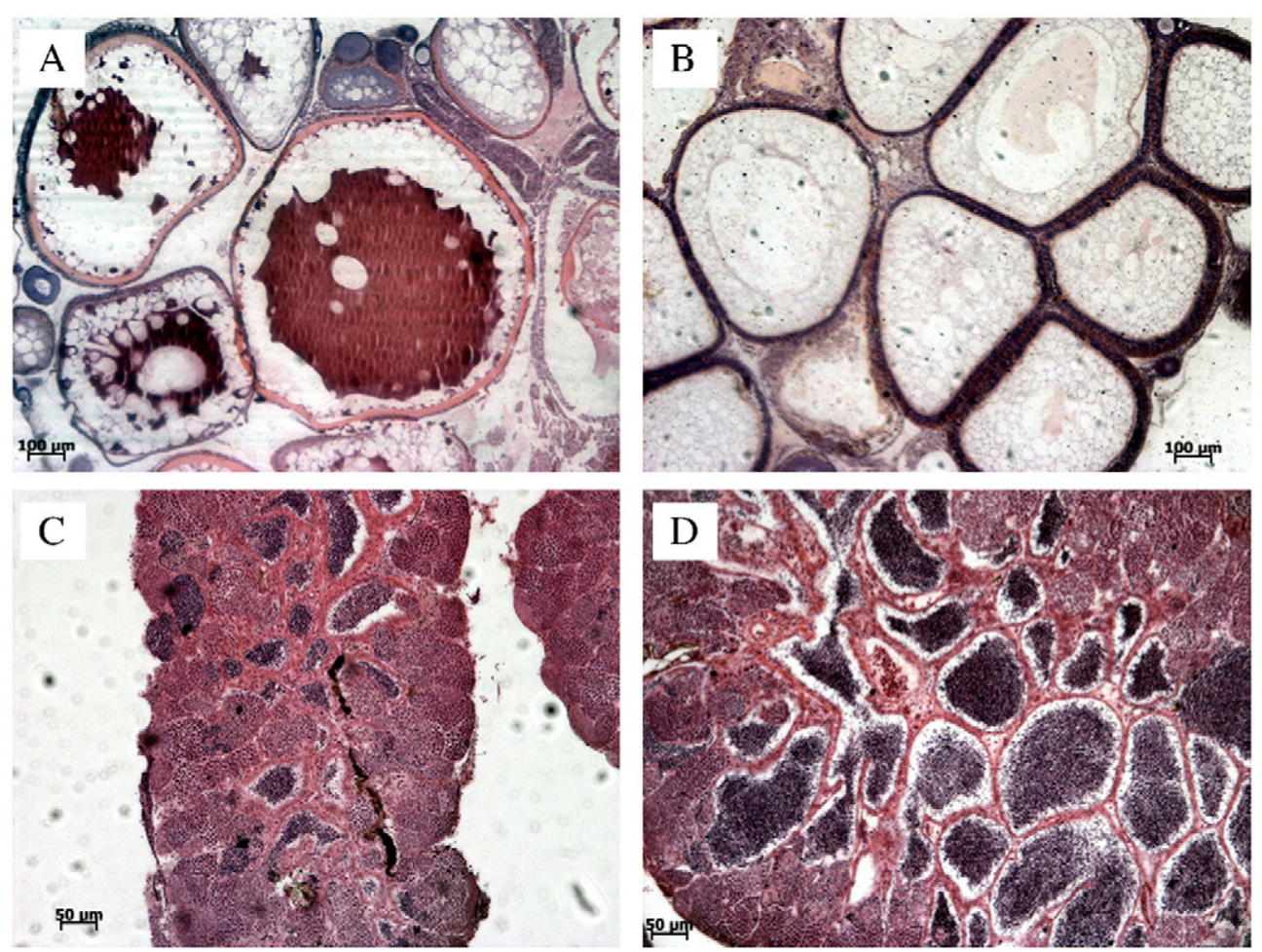

Fig. 2. Histological section of the gonad of mature medaka in letrozole exposure experiment, stained with hematoxylin and ecosin. A: Section of ovary from a control female showing oocytes at various stages of maturation. B: Section of ovary from a female exposed to letrozole $(625 \mu \mathrm{g} / \mathrm{L})$ showing abundance of small oocytes that lack dense-staining material. C: Section of testis from a control male. D: Section of testis from a male exposed to letrozole $(625 \mu \mathrm{g} / \mathrm{L})$. Note the enlargement of the lumina of the seminiferous tubules and an increase in the density of spermatozoa.

exposure group $(625 \mu \mathrm{g} / \mathrm{L})$. Ovaries of the control females contained oocytes at various stages of maturation consistent with asynchronous oogenesis. In comparison, no female medaka in the $625 \mu \mathrm{g} / \mathrm{L}$ group had normal mature oocytes. The increase of GSI of female medaka exposed to letrozole (Fig. 1) corresponded with the abundant accumulation of small-sized oocytes.

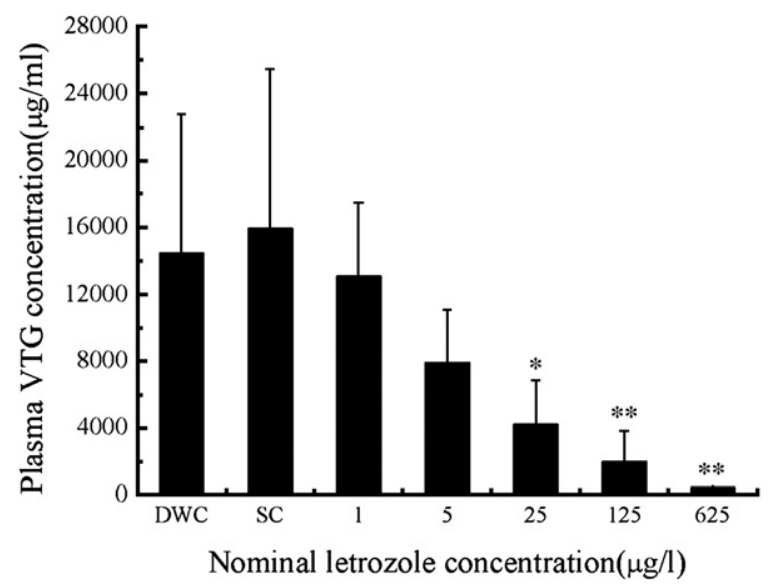

Fig. 3. Plasma vitellogenin (VTG) concentrations of female medaka after exposure to letrozole for 21 days. Values are shown as the mean VTG concentrations of female fish. Error bars represent the standard deviation of the mean. The asterisk symbols $\left(*\right.$ and $\left.{ }^{* *}\right)$ denote significantly different when compared to the controls as $p<0.05$ and $p<0.01$, respectively. DWC: diluted water control; SC: solvent control.
The testicular development of male medaka exposed to letrozole was affected as well. Histologically, there was an enlargement of the lumina of the seminiferous tubules and an increase in the density of spermatozoa which was particularly prevalent in males from the highest test concentration $(625 \mu \mathrm{g} / \mathrm{L})$.

Plasma VTG concentrations in male medaka were near the limit of detection and were unaffected by exposure to letrozole (data not shown). However, there was a dose-dependent

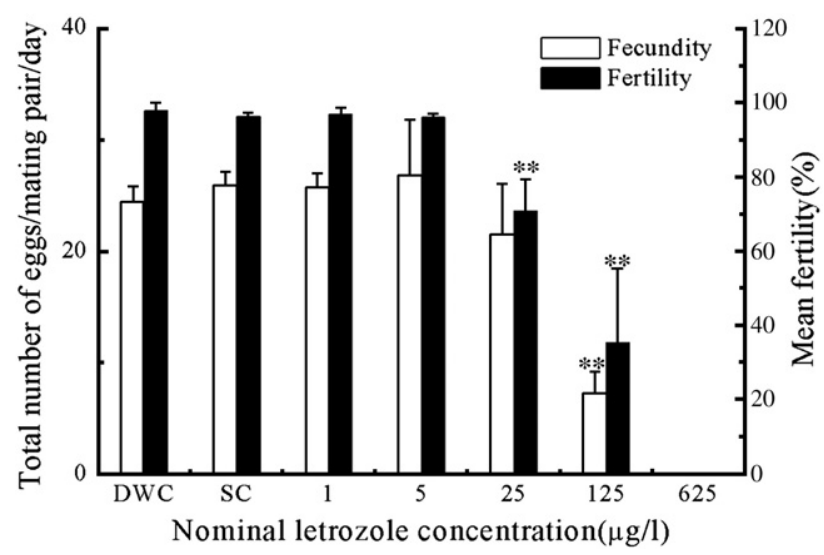

Fig. 4. The fecundity and the fertility of eggs from paired mature medaka in the last week of 21-day letrozole exposure period. Error bars represent the standard deviation of the mean. The asterisk symbol $(* *)$ denotes significantly different when compared to the controls as $p<0.01$. DWC: diluted water control; SC: solvent control. 
Table 3

Hatchability, time to hatching, gross abnormality rate and sex ratio in the F1 generation of fertilized eggs from F0 generation medaka exposed to letrozole for 21 days

\begin{tabular}{lllll}
\hline $\begin{array}{l}\text { Nominal } \\
\text { concentration } \\
(\mu \mathrm{g} / \mathrm{L})\end{array}$ & $\begin{array}{l}\text { Hatchability } \\
(\%)\end{array}$ & $\begin{array}{l}\text { Time to } \\
\text { hatching } \\
\text { (days) }\end{array}$ & $\begin{array}{l}\text { Gross } \\
\text { abnormality } \\
\text { rate }(\%)\end{array}$ & $\begin{array}{l}\text { Sex ratio } \\
(\%, \mathrm{M}: \mathrm{F})\end{array}$ \\
\hline $\mathrm{DWC}$ & $90.5 \pm 4.1$ & $9.24 \pm 0.18$ & $2.1 \pm 2.5$ & $52: 48$ \\
$\mathrm{SC}$ & $89.6 \pm 7.2$ & $9.25 \pm 0.33$ & $0.8 \pm 1.5$ & $48: 52$ \\
1 & $90.8 \pm 6.9$ & $9.37 \pm 0.02^{*}$ & $2.8 \pm 3.6$ & $52: 48$ \\
5 & $94.2 \pm 5.0$ & $9.32 \pm 0.12$ & $2.5 \pm 3.2$ & $59: 41$ \\
25 & $72.5 \pm 4.2 * *$ & $9.52 \pm 0.21^{* *}$ & $4.7 \pm 3.7$ & $65: 35^{*}$ \\
125 & 0 & & & \\
$625^{\text {a }}$ & & & & \\
\hline
\end{tabular}

Data are the mean \pm S.D. The asterisk symbols $(*$ and $* *)$ denote significantly different when compared to the controls as $p<0.05$ and $p<0.01$, respectively. DWC: diluted water control; SC: solvent control.

${ }^{a}$ F0 generation medaka ceased spawning.

decrease in plasma VTG concentration of the females exposed to letrozole (Fig. 3). Significant decreases were observed in the 25,125 and $625 \mu \mathrm{g} / \mathrm{L}$ groups when compared to the controls $(p<0.05, p<0.01$ and $p<0.01$, respectively). At the highest concentration of letrozole, plasma VTG decreased to approximately $3 \%$ of control values.

\subsubsection{Reproductive effects}

In the highest exposure group $(625 \mu \mathrm{g} / \mathrm{L})$, the medaka did not spawn during the last week of exposure (Fig. 4). Compared to that of the controls, both fecundity and fertility decreased significantly in the $125 \mu \mathrm{g} / \mathrm{L}$ group $(p<0.01)$. Fecundity in the $25 \mu \mathrm{g} / \mathrm{L}$ letrozole group decreased slightly, but fertility was significantly lower than in controls $(p<0.01)$. In the low exposure groups $(5 \mu \mathrm{g} / \mathrm{L}$ and $1 \mu \mathrm{g} / \mathrm{L})$, no significant differences were observed in fecundity and fertility when compared to those of the controls.

In the $125 \mu \mathrm{g} / \mathrm{L}$ group, no fertilized eggs hatched (Table 3). The embryonic hatching in those exposed to $25 \mu \mathrm{g} / \mathrm{L}$ letrozole showed adverse effects $(p<0.01)$, but in those exposed to the lowest letrozole concentration, hatchability tended to increase slightly. This increase, however, was not statistically significant. Time to hatching for embryos exposed to $1 \mu \mathrm{g} / \mathrm{L}$ and $25 \mu \mathrm{g} / \mathrm{L}$ was significantly delayed relative to the controls $(p<0.05$ and $p<0.01$, respectively). In the $5 \mu \mathrm{g} / \mathrm{L}$ treatment group, time to hatching was also delayed, although was not statistically significant. There was a dose-dependent increase in the proportion of males in the F1 generation of fertilized eggs from paired F0 generation medaka exposed to letrozole. The sex ratio tended to favor males at $5 \mu \mathrm{g} / \mathrm{L}$ and the effect was significant at $25 \mu \mathrm{g} / \mathrm{L}(p<0.05)$. Gross abnormalities were unchanged with exposure to letrozole.

\section{Discussion}

The present study comprehensively assessed the effects of letrozole on reproductive fitness and early life stages of Japanese medaka. Under the conditions of these experiments, exposure to letrozole for 21 days affected the reproductive capacity, gonadal development, vitellogenin production of females, and caused transgenerational effects in their progeny. Furthermore, in results to be published separately, we confirmed that letrozole could cause significant inhibition of brain aromatase (CYP19b) expression in both sexes using real-time quantitative RT-PCR. The results obtained in the present study are consistent with the AI action of letrozole on the formation of estrogen adversely affecting the whole organism.

The fact that embryonic development was not affected in the egg exposure study (Table 1) while the reproductive effects included decreased hatchability (Table 3), suggests that adult exposure is critical. Letrozole is a moderately hydrophobic compound $(\log P=3.385)$ which readily dissolves in apolar solvents and is slightly water-soluble. These properties suggest that letrozole would be rapidly assimilated by adults and would easily partition through aqueous compartments (e.g. blood, cytosol) into nonpolar compartments (e.g. membranes, yolk). Thus, biologically significant exposure of gonads may have occurred in the reproductive study.

Numerous small-diameter oocytes were observed in the letrozole-exposed females (Fig. 2) and these may have been VTG-deficient mature oocytes. The AI action of letrozole would effectively decrease VTG synthesis, which was confirmed by the decrease in female plasma VTG (Fig. 3), blocking the oocyte growth phase.

While letrozole affected VTG accumulation in oocytes, it may not have affected other aspects of oocyte maturation. E2 synthesis is normally downregulated at the outset of oocyte maturation by a sharp decrease in aromatase activity (Nagahama et al., 1994). Similarly, letrozole inhibition of E2 synthesis in the ovaries would be expected to relax adenohypohyseal retroinhibition of the gonadotrophin, luteinizing hormone (LH). An LH pulse normally triggers maturation-initiating substances (MIS) synthesis in the ovary which reactivates meiosis I (Jalabert et al., 1991). E2 is not required for oocyte maturation (Mishra and Joy, 2006a) although its metabolite, 2hydroxyestradiol-17 $\beta\left(2-\mathrm{OHE}_{2}\right)$ demonstrates MIS properties (Mishra and Joy, 2006b). Endogenous MIS have been identified in several teleosts as $17 \alpha, 20 \beta$-dihydroxy-4-pregnen-3-one and $17 \alpha, 20 \beta, 21$-trihydroxy-4-pregnen-3-one (Nagahama et al., 1993) and their synthesis is independent of E2.

Alternatively, letrozole may have inhibited oogenesis before the oocyte maturation stage which would explain the numerous small oocytes and the decrease in fecundity (Fig. 4). Other investigations have reported that EDCs can specifically affect the oocyte maturation stage. For example, Tokumoto et al. (2005) using zebrafish oocytes in vitro demonstrated that EDCs could either mimic MIS action to stimulate oocyte maturation (diethylstilbesterol, tamoxifen, 4-hydroxytamoxifen) or inhibit MIS-induction of oocyte maturation (pentachlorophenol, methoxychlor).

It is notable that a concentration-dependent increase of genotypic males occurred in the F1 generation of fertilized eggs from exposed F0 adults. Sex inversions in fish exposed to EDCs have been reported previously (Yamamoto, 1953; Edmunds et al., 2000; Iwamatsu et al., 2000; Kitano et al., 2000) and may involve androgenic chemicals eliciting male characteristics in 
females or estrogenic chemicals producing female traits in males. Further, the inhibition of aromatase, with consequent lower estrogen synthesis, could induce females to develop into functional males and result in a predominantly male population. This mechanism is supported by experiments of European pond turtle (Emys orbicularis) (Richard-Mercier et al., 1995; Belaid et al., 2001), red spotted grouper (Epinephelus akaara) (Li et al., 2005), chinook salmon (Oncorhynchus tshawytscha) (Piferrer et al., 1994), Japanese flounder (Paralichthys olivaceus) (Kitano et al., 2000) and zebrafish (Danio rerio) (McAllister and Kime, 2003; Andersen et al., 2004; Fenske and Segner, 2004) with different life stages exposed to AIs. However, some uncertainties remain. Kawahara and Yamashita (2000) reported that medaka eggs incubated with an AI resulted in no abnormal sex ratios. In a more recent study (Kuhl and Brouwer, 2006), the results demonstrated that immersion exposure to AIs alone did not result in any female-to-male inversions of medaka, even though aromatase activity was inhibited. Therefore, altered aromatase activity levels are not a requirement for sex inversion in fish (Kuhl and Brouwer, 2006).

However, as far as we know, alteration of the genotypic sex ratio in fish has never been reported. A similar result was observed recently in our laboratory in medaka exposed to tamoxifen, a selective estrogen-receptor modulator. It should be noted that in the reproductive study, eggs were collected several hours after spawning such that the eggs were directly exposed to the toxicant for a few hours. Since letrozole had no adverse effects on embryonic development in the egg exposure study, it is presumed that the change in sex ratio may be caused by differential sensitivity of spermatozoa (i.e. the spermatozoa with the $\mathrm{X}$ chromosome may be more sensitive to letrozole than the $\mathrm{Y}$ chromosome) resulting in more spermatozoa with Y chromosome. Obviously, further studies into the related mechanism are essential.

It is interesting that letrozole caused an increase in HSI in the male medaka, but a decrease in females. It is well known that liver is the primary detoxification organ, and the toxicants will induce both hypertrophy and hyperplasia of hepatocytes resulting in hepatomegaly. This could be the reason for the increase in HSI in the males. On the other hand, synthesis of VTG is under estrogen control mediated by estrogen receptors in the liver, and the weight of the liver will increase substantially due to the accumulation of VTG (Zaroogian et al., 2001). Therefore, the decrease of HSI in the females was consistent with exposure to letrozole which inhibits aromatase activity and in turn decreases the synthesis of VTG.

VTG is generally accepted as a suitable biomarker for evaluating the effects of EDCs in fish, and most attention has been on the change of VTG in males or juveniles for estrogenic effects because the VTG level appears to oscillate during the spawning cycle in the female. From the results of the present study, however the significant decrease of VTG levels in females (Fig. 3) suggests that measuring the VTG levels in females could be a powerful tool for anti-estrogenic effects. Moreover, the decrease in plasma VTG may be associated with poor egg quality and lower hatchability (Table 3). Similarly, Ankley et al. (2002) reported that VTG levels decreased in female fathead minnows (Pimephales promelas) exposed to the AI fadrozole. In contrast, Shilling et al. (1999) found that letrozole did not block vitellogenin production of E2 synthesis in juvenile rainbow trout (Oncorhynchus mykiss) at doses up to $1 \mathrm{mg} / \mathrm{kg}$. In an another study of fadrozole using juvenile fathead minnows, concentrations up to $100 \mu \mathrm{g} / \mathrm{L}$ did not reduce VTG synthesis (Panter et al., 2002).

Previous studies showed that aromatase inhibition changed tissue steroid levels as well. The study of Afonso et al. (1999) provided the first evidence that injection of the AI fadrozole was effective in vivo in lowering plasma E2 levels, and demonstrated a shift from E2 to $17 \alpha, 20 \beta-P$ biosynthesis in AI-injected female coho salmon (Oncorhynchus kisutch). On the other hand, fadrozole inhibited E2 secretion in the brain of male salmon, and caused a premature and transient increase in plasma17 $\alpha, 20 \beta-P$ levels (Afonso et al., 2000). Similarly, it was found that concentrations of fadrozole ranging from to 2 to $50 \mu \mathrm{g} / \mathrm{L}$ could lower E2 levels in female fathead minnows in a dose-dependent manner, and both 11-KT and T were significantly elevated in males (Ankley et al., 2002).

Letrozole can enter the aquatic environment following manufacture, or ingestion/excretion. Although most of letrozole ingested can be eliminated after metabolism by cytochrome P450 isozymes into a pharmacologically inactive carbinol metabolite, approximately $6 \%$ of the dose remains unchanged (Haynes et al., 2003). Unfortunately, there are no data of environmental concentrations available as yet for letrozole, but the occurrence of another antiestrogen used in breast cancer therapy, i.e. tamoxifen, was reported. The concentrations of tamoxifen ranged between 0.146 and $0.369 \mu \mathrm{g} / \mathrm{L}$ in municipal sewage effluents, while between 0.027 and $0.212 \mu \mathrm{g} / \mathrm{L}$ were detected in estuarine waters in the U.K. (Fent et al., 2006). Studies have demonstrated that letrozole has superior efficacy to tamoxifen for endocrine therapy, and is likely to be an alternative or complement of the latter in the clinical use (Brodie et al., 1999; Nunez et al., 2004). Furthermore, since tamoxifen is light-sensitive and extensively metabolized (MacCallum et al., 1996) while letrozole is more stable, the potential of letrozole to pose a risk in the environment is greater.

Results of the present study, coupled with previous research, demonstrate that inhibition of aromatase in fish could result in significant adverse effects on endocrine function and reproduction. However, as we mentioned above, the concentrations of letrozole used in this laboratory study may be greater than that would be expected in environmental samples. On the other hand, it is highly unlikely that fish inhabiting natural environments are exposed to a single AI. Even if letrozole alone may not adversely affect the reproduction of fish populations, the joint effects of the combination of AIs and other EDCs in the aquatic environment should be determined. Therefore, the long-term effects in fish exposed to environmentally relevant concentrations (i.e. lower concentrations) of letrozole, and co-exposed to other AIs or EDCs with other mechanisms should be evaluated in future studies.

\section{Acknowledgements}

We gratefully acknowledge the supports of National Basic Research Program (2007CB407304) and National Natural Science Foundation of China $(50538090,20337020)$ for conducting this research. 


\section{References}

Afonso, L.O.B., Iwama, G.K., Smith, J., Donaldson, E.M., 1999. Effects of the aromatase inhibitor fadrozole on plasma sex steroid secretion and ovulation rate in female coho salmon, Oncorhynchus kisutch, close to final maturation. Gen. Comp. Endocrinol. 113, 221-229.

Afonso, L.O.B., Iwama, G.K., Smith, J., Donaldson, E.M., 2000. Effects of the aromatase inhibitor fadrozole on reproductive steroids and spermiation in male coho salmon (Oncorhynchus kisutch) during sexual maturation. Aquaculture 188, 175-187.

Andersen, L., Kinnberg, K., Holbech, H., Korsgaard, B., Bjerregaard, P., 2004. Evaluation of a 40 day assay for testing endocrine disrupters: effects of an antiestrogen and an aromatase inhibitor on sex ratio and vitellogenin concentrations in juvenile zebrafish (Danio rerio). Fish Physiol. Biochem. 30, 257-266.

Ankley, G.T., Kahl, M.D., Jensen, K.M., Hornung, M.W., Korte, J.J., Makynen, E.A., Leino, R.L., 2002. Evaluation of the aromatase inhibitor fadrozole in a short-term reproduction assay with the fathead minnow (Pimephales promelas). Toxicol. Sci. 67, 121-130.

Ashton, D., Hilton, M., Thomas, K.V., 2004. Investigating the environmental transport of human pharmaceuticals to streams in the United Kingdom. Sci. Total Environ. 333, 167-184.

Belaid, B., Richard-Mercier, N., Pieau, C., Dorizzi, M., 2001. Sex reversal and aromatase in the European pond turtle: treatment with letrozole after the thermosensitive period for sex determination. J. Exp. Zool. 290, 490-497.

Brion, F., Nilsen, B.M., Eidem, J.K., Goksoyr, A., Porcher, J.M., 2002. Development and validation of an enzyme-linked immunosorbent assay to measure vitellogenin in the zebrafish (Danio rerio). Environ. Toxicol. Chem. 21, 1699-1708.

Brodie, A., Lu, Q., Long, B., 1999. Aromatase and its inhibitors. J. Steroid Biochem. 69, 205-210.

Chikae, M., Hatano, Y., Ikeda, R., Morita, Y., Hasan, Q., Tamiya, E., 2004. Effects of bis(2-ethylhexyl) phthalate and benzo[ $a]$ pyrene on the embryos of Japanese medaka (Oryzias latipes). Environ. Toxicol. Pharmacol. 16, 141-145.

Edmunds, J.S., Mccarthy, R.A., Ramsdell, J.S., 2000. Permanent and functional male-to-female sex reversal in d-rR strain medaka (Oryzias latipes) following egg microinjection of $o, p^{\prime}$-DDT. Environ. Health Perspect. 108, 219-224.

Fenske, M., Segner, H., 2004. Aromatase modulation alters gonadal differentiation in developing zebrafish (Danio rerio). Aquat. Toxicol. 67, $105-126$

Fent, K., Weston, A.A., Caminada, D., 2006. Ecotoxicology of human pharmaceuticals. Aquat. Toxicol. 76, 122-159.

Halling-Sorensen, B., Nors Nielsen, S., Lanzky, P.F., Ingerslev, F., Holten Lutzhoft, H.C., Jorgensen, S.E., 1998. Occurrence, fate and effects of pharmaceutical substances in the environment-A review. Chemosphere 36, 357-393.

Haynes, B.P., Dowsett, M., Miller, W.R., Dixon, J.M., Bhatnagar, A.S., 2003. The pharmacology of letrozole. J. Steroid Biochem. 87, 35-45.

Hilton, M.J., Thomas, K.V., 2003. Determination of selected human pharmaceutical compounds in effluent and surface water samples by highperformance liquid chromatography-electrospray tandem mass spectrometry. J. Chromatogr., A 1015, 129-141.

Howell, A., Buzdar, A., 2005. Are aromatase inhibitors superior to antiestrogens? J. Steroid Biochem. 93, 237-247.

Ishibashi, H., Matsumura, N., Hirano, M., Matsuoka, M., Shiratsuchi, H., Ishibashi, Y., Takao, Y., Arizono, K., 2004. Effects of triclosan on the early life stages and reproduction of medaka Oryzias latipes and induction of hepatic vitellogenin. Aquat. Toxicol. 67, 167-179.

Iwamatsu, T., Kobayashi, H., Hamaguchi, S., Sagegami, R., Shuo, T., 2000. Sex reversal of medaka (Oryzias latipes) by a short exposure of embryos to sex steroids. Zool. Sci. 17, 15.

Jalabert, B., Fostier, A., Breton, B., Weil, C., 1991. Oocyte maturation in vertebrates. In: Pang, P.K.T., Schreibman, M.P. (Eds.), Vertebrate Endocrinology: Fundamentals and Biomedical Implications, vol. 4A. Academic Press, New York, pp. 23-90.

Kang, I.J., Yokota, H., Oshima, Y., Tsuruda, Y., Oe, T., Imada, N., Tadokoro, H., Honjo, T., 2002. Effects of bisphenol A on the reproduction of Japanese medaka (Oryzias latipes). Environ. Toxicol. Chem. 21, 2394-2400.
Kawahara, T., Yamashita, I., 2000. Estrogen-independent ovary formation in the medaka fish, Oryzias latipes. Zool. Sci. 17, 65-68.

Kitano, T., Takamune, K., Nagahama, Y., Abe, S.-I., 2000. Aromatase inhibitor and $17 \alpha$-methyltestosterone cause sex-reversal from genetical females to phenotypic males and suppression of $\mathrm{P} 450$ aromatase gene expression in Japanese flounder (Paralichthys olivaceus). Mol. Reprod. Dev. 56, 1-5.

Kuhl, A.J., Brouwer, M., 2006. Antiestrogens inhibit xenoestrogen-induced brain aromatase activity but do not prevent xenoestrogen-induced feminization in Japanese medaka (Oryzias latipes). Environ. Health Perspect. 114, 500-506.

Kuhl, A.J., Manning, S., Brouwer, M., 2005. Brain aromatase in Japanese medaka (Oryzias latipes): Molecular characterization and role in xenoestrogen-induced sex reversal. J. Steroid Biochem. 96, 67-77.

Li, G.-L., Liu, X.-C., Lin, H.-R., 2005. Aromatase inhibitor letrozole induces sex inversion in the protogynous red spotted grouper (Epinephelus akaara). Acta Physiol. Sin. 57, 473-479 (in Chinese with English abstract).

Marfil, F., Pineau, V., Sioufi, A., Godbillon, J., 1996. High-performance liquid chromatography of the aromatase inhibitor,letrozole, and its metabolite in biological fluids with automated liquid-solid extraction and fluorescence detection. J. Chromatogr., B, Biomed. Sci. Appl. 683, 251-258.

McAllister, B.G., Kime, D.E., 2003. Early life exposure to environmental levels of the aromatase inhibitor tributyltin causes masculinisation and irreversible sperm damage in zebrafish (Danio rerio). Aquat. Toxicol. 65, 309-316.

MacCallum, J., Cummings, J., Dixon, J.M., Miller, W.R., 1996. Solid-phase extraction and high-performance liquid chromatographic determination of tamoxifen and its major metabolites in plasma. J. Chromatogr., B, Biomed. Sci. Appl.. 678, 317-323.

Melo, A.C., Ramsdell, J.S., 2001. Sexual dimorphism of brain aromatase activity in medaka: induction of a female phenotype by estradiol. Environ. Health Perspect. 109, 257-264.

Mishra, A., Joy, K.P., 2006a. Relative effects of estradiol-17ß (E2), catecholestrogens and clomiphene citrate on in vitro oocyte maturation in the catfish Heteropneustes fossilis (Bloch) and E2 inhibition of 2hydroxyestradiol-induced maturation. Gen. Comp. Endocrinol. 147, 141-149.

Mishra, A., Joy, K.P., 2006b. 2-Hydroxyestradiol-17ß-induced oocyte maturation in catfish (Heteropneustes fossilis) involves protein kinase $\mathrm{C}$ and its interaction with protein phosphatases. Comp. Biochem. Physiol., A 144, $416-422$.

Nagahama, Y., Yoshikuni, M., Yamashita, M., Sakai, N., Tanaka, M., 1993. Molecular endocrinology of oocyte growth and maturation in fish. Fish Physiol. Biochem. 11, 3-14.

Nagahama, Y., Yoshikuni, M., Yamashita, M., Tanaka, M., 1994. Regulation of oocyte maturation in fish. Fish Physiol. XIII, 393-439.

Nimrod, A.C., Benson, W.H., 1998. Reproduction and development of Japanese medaka following an early life stage exposure to xenoestrogens. Aquat. Toxicol. 44, 141-156.

Noaksson, E., Tjarnlund, U., Bosveld, A.T.C., Balk, L., 2001. Evidence for endocrine disruption in perch (Perca fluviatilis) and roach (Rutilus rutilus) in a remote Swedish lake in the vicinity of a public refuse dump. Toxicol. Appl. Pharmacol. 174, 160-176.

Nunez, N.P., Jelovac, D., Macedo, L., Berrigan, D., Perkins, S.N., Hursting, S.D., Barrett, J.C., Brodie, A., 2004. Effects of the antiestrogen tamoxifen and the aromatase inhibitor letrozole on serum hormones and bone characteristics in a preclinical tumor model for breast cancer. Clin. Cancer Res. 10, 5375-5380.

Packard, G.C., Boardman, T.J., 1999. The use of percentages and size-specific indices to normalize physiological data for variation in body size: wasted time, wasted effort? Comp. Biochem. Physiol., A 122, 37-44.

Panter, G.H., Hutchinson, T.H., Lange, R., Lye, C.M., Sumpter, J.P., Zerulla, M., Tyler, C.R., 2002. Utility of a juvenile fathead minnow screening assay for detecting (anti-)estrogenic substances. Environ. Toxicol. Chem. 21, 319-326.

Patyna, P.J., Davi, R.A., Parkerton, T.F., Brown, R.P., Cooper, K.R., 1999. A proposed multigeneration protocol for Japanese medaka (Oryzias latipes) to evaluate effects of endocrine disruptors. Sci. Total Environ. 233, 211-220.

Pfister, C.U., Duval, M., Godbillon, J., Gosset, G., Gygax, D., Marfil, F., Sioufi, A., Winkler, B., 1994. Development, application and comparison of an 
enzyme immunoassay and a high-performance liquid chromatography method for the determination of the aromatase inhibitor CGS 20267 in biological fluids. J. Pharm. Sci. 83, 520-524.

Piferrer, F., Zanuy, S., Carrillo, M., Solar, I.I., Devlin, R.H., Donaldson, E.M., 1994. Brief treatment with an aromatase inhibitor during sex-differentiation causes chromosomally female salmon to develop as normal, functional males. J. Exp. Zool. 270, 255-262.

Richard-Mercier, N., Dorizzi, M., Desvages, G., Girondot, M., Pieau, C., 1995. Endocrine sex reversal of gonads by the aromatase inhibitor letrozole (CGS 20267) in Emys orbicularis, a turtle with temperature-dependent sex determination. Gen. Comp. Endocrinol. 100, 314-326.

Seralini, G.-E., Moslemi, S., 2001. Aromatase inhibitors: past, present and future. Mol. Cell. Endocrinol. 178, 117-131.

Shilling, A.D., Carlson, D.B., Williams, D.E., 1999. Rainbow trout, Oncorhynchus mykiss, as a model for aromatase inhibition. J. Steroid Biochem. 70, 89-95.
Smith, I.E., 1999. Aromatase inhibitors: a dose-response effect? Endocr. Relat. Cancer 6, 245-249

Tokumoto, T., Tokumoto, M., Nagahama, Y., 2005. Induction and inhibition of oocyte maturation by EDCs in zebrafish. Reprod. Biol. Endocrinol. 3, 69.

U.S.EPA, 2002. Draft Detailed Review Paper on Fish Screening Assays for Endocrine Disruption. Columbus, Ohio.

Yamamoto, T., 1953. Artificially induced sex-reversal in genotypic males of the medaka (Oryzias latipes). J. Exp. Zool. 123, 571-594.

Zaroogian, G., Gardner, G., Borsay Horowitz, D., Gutjahr-Gobell, R., Haebler, R., Mills, L., 2001. Effect of $17 \beta$-estradiol, $o, p^{\prime}$-DDT, octylphenol and $p, p^{\prime}-$ DDE on gonadal development and liver and kidney pathology in juvenile male summer flounder (Paralichthys dentatus). Aquat. Toxicol. 54, $101-112$. 